\title{
New Business Model as Response to Competition from Emerging Economies
}

\subsection{Emergence of Threats Associated with Rise of Emerging Economies}

Low economic growth has been estimated for developed countries, including Japan, because of decreasing population growth rate, with no future prospects for large market expansion. On the other hand, the rise of economic growth in developing countries, such as China and India, provide great opportunities for Japanese companies. However, a high rate of economic growth can be realized in developing countries only by catching up technologically with developed countries, and establishing competitive local companies that adopt modern management techniques used in developed countries. Therefore, in addition to providing opportunities for Japanese companies, the growth of developing countries indicates the threat of new competitors in international markets.

In particular, companies are technologically catching up and the shift among the players in the international high-tech market is evident. This indicates a high rate of technological innovation. For example, the dynamic random-access memory (DRAM) of Japanese electronics companies had a virtual monopoly in the international market during the 1980s and first half of the 1990s. However, in the 1990s, Japanese companies faced fierce competition from Samsung and other Korean companies, forcing them to exit the DRAM market. By 2012, Elpida, the last Japanese company in that market, sought protection under the Corporate Restructuring Act, leaving Japan with no DRAM manufacturers. Within semiconductor integrated circuits (ICs), DRAM is a relatively standardized product, and thus Japanese companies were unable to compete with Korean companies in terms of prices. Korean companies were able to lower their prices by large-scaled investments in equipment. As a backdrop, manufacturing technologies for ICs became incorporated into manufacturing equipment. The traditional model of IC manufacturers maintaining 
competitiveness through manufacturing technology gave way to a model of price competitiveness through investments in the most advanced manufacturing equipment.

DRAMs are manufactured on the order of microns, and technologically catching up with other manufacturers in areas such as chipset integration and yield improvement is difficult. Thus, companies from China and other developing countries are not yet at the front line of international markets. However, as stated in Chap. 1, Chinese solar panel manufacturers, such as Suntech and JA Power, already hold the highest global market share in terms of production volume. Silicon crystal-based solar panels are manufactured using processes similar to those used in the semiconductor industry, although the processes do not require highly precise technology as in DRAM. In addition, because companies can purchase turnkey production lines, cost competitiveness is more important than a manufacturer's technological capability. As a result, costs (e.g., land, buildings, wages), excluding manufacturing equipment costs, are relatively cheap in developing countries, making products manufactured there more competitive in international markets. Chinese companies have rapidly increased their market shares, leaving Japanese and German companies, formerly the world's top manufacturers, behind.

While Japan has no DRAM manufacturers within its semiconductor industry, Japanese companies are still internationally competitive in logic circuits markets used for specific applications such as electronic products and automobiles. However, similar to the flow of water from higher to lower levels, technological catch-up will eventually take place as Korean companies, followed by Chinese companies, close the gap. Accordingly, Japanese companies must differentiate their products with more advanced technology to respond to the competition from more cost competitive companies in developing countries.

Furthermore, it should be kept in mind that a high level of competitiveness alone is insufficient when competing against companies from developing countries. Using the example of the hard disk industry, Christensen showed the "Innovator's Dilemma" regarding products from companies with superior technology being driven out of a market by late entrants through "destructive innovation" (Christensen 2001). This occurs when the pace of technological innovation exceeds the technological standards demanded by customers. Companies owning advanced technology are strongly tempted to advance their own technology to differentiate themselves from the competition; however, the average consumer views these products as too advanced for their needs. At this stage, a company will not increase its competitive advantage by making further investments to increase its level of technology. Rather, providing low-cost products at the level of technology demanded by customers will maximize its value to those customers. In particular, in developing markets such as China and India, wage levels are lower than those in developed countries, requiring a product strategy that targets the "good-enough" market in the volume zone. Thus, it is likely that a product differentiation strategy based on technology will not work.

For Japanese companies to respond to the threats accompanying the rise of developing countries, they must consider not only technological advancement but also the overall business model. After World War II, Japanese manufacturers rapidly 
caught up with their European and US counterparts and become competitive in international markets. Through that process, the guiding principle was that only by improving product performance and quality through technology can the value to the customer be improved. However, when competing with countries, such as Korea and China, that followed Japan as well as in "good-enough" markets in developing countries such as China and India, the philosophy of "make good products and they will sell" often did not apply. Two important perspectives when evaluating business models in developing countries are "maximizing value creation for customers" and "product and service design that is difficult to replicate by companies in developing countries." After discussing the basic concepts behind these two philosophies, we discuss specific policies to realize them. Finally, we discuss infrastructure-related services as an example of system integration services structured as difficult-toreplicate products and services. In particular, we discuss the issues encountered by Japanese companies overseas in the railroad industry and possible policies in response to these issues.

\subsection{Moving from a "Product-Centric" to a "Customer Value" Model}

The idea of "make good products and they will sell" stems from manufacturers on the supply side of a product, and is effective in case of a relatively high level of customer demand in relation to the product's current state. However, as seen in "The Innovator's Dilemma" by Christensen, particularly in products with high rates of technological progress, the products exceed the level of customer technology demands, causing the products to lose its effectiveness. For example, every time Microsoft releases a new version of Windows, it adds new functions. However, because of Microsoft's focus on the design for Windows Vista, the consumers rated it poorly as a slow-responding system; subsequently, for the design of Windows 7, Microsoft focused on the lightness of the operating environment. Within the hightech industry of electronics and software, companies are often product-centric, with an obsession for product performance and functionality. In developing countries, such as China and India, with growing markets, the average demand for product technology is often lower than that of developing countries. In these markets, companies must switch from a product-centric strategy to a "customer value model" that aims to maximize value to the customer.

Thus, it is helpful that these companies refer to "Service-Centered Logic for Marketing" (Vargo and Lusch 2004). This publication is an antithesis to traditional marketing theory built on product transactions and centers on the services that customers gain from products. As can be seen in Table 5.1, according to the traditional marketing theory (under the product-centric model), products are the prime movers of business transactions, whose values are set by the companies that provide them. For example, the $4 \mathrm{P}$ marketing theory is a tool that examines a product, including its price, place, and promotion from the manufacturers' perspective (see Chap. 9 for more information). 
Table 5.1 Comparison of product-centric and service-centric models

\begin{tabular}{l|l|l}
\hline $\begin{array}{l}\text { Unit of market } \\
\text { exchange }\end{array}$ & Product-centric model & Service-centric model \\
\hline Product role & $\begin{array}{l}\text { Key component of market } \\
\text { exchange }\end{array}$ & $\begin{array}{l}\text { Specialized knowledge and skills } \\
\text { embodied in the services and products } \\
\text { that customers gain }\end{array}$ \\
\hline Customer role & Receiver of product & $\begin{array}{l}\text { Intermediary that creates customer } \\
\text { value }\end{array}$ \\
\hline $\begin{array}{l}\text { Determiner of } \\
\text { value }\end{array}$ & $\begin{array}{l}\text { Corporations (value is attached } \\
\text { to the product itself) } \\
\text { pollaborator in services gained from }\end{array}$ & $\begin{array}{l}\text { Customer (value determined by benefit } \\
\text { gained by customer; corporations are } \\
\text { nothing more than proposers of value) }\end{array}$ \\
\hline $\begin{array}{l}\text { Source of value } \\
\text { added services }\end{array}$ & $\begin{array}{l}\text { Surplus created from } \\
\text { exchanges of tangible products } \\
\text { and management resources }\end{array}$ & $\begin{array}{l}\text { Surplus created by exchanges of } \\
\text { specialized knowledge and skills from } \\
\text { products and services }\end{array}$ \\
\hline
\end{tabular}

Source: Compiled from Vargo and Lusch (2004), Table 2

In contrast, the new marketing theory proposed by Vargo et al. (i.e., the servicecentric model) focuses on the service gained by the consumer using a product, with products as a means to which services are provided. Thus, the key component of an exchange in the market place is not the product itself, but the specialized knowledge and skills to implement the services that products provide as intermediaries. The specialized knowledge and skills are provided not only by the companies but also by the consumers, with consumers as collaborators in the creation of the product. In addition, it is ultimately the consumers that determine the value of these services, in contrast to the product-centric model, whose theory is from the viewpoint of the companies as providers Table 5.1.

Using Microsoft Windows as an example, companies should not provide products in which the focus lies on the design and functionality; rather, they should provide services that focus on the benefits that customers derive through the use of Windows. Windows is a computer operating system, which by itself has no utility. However, it is the base software that users need to browse the Internet, create documents, and perform other tasks. From the user's perspective, the services required from an operating system that would result in improved customer value are clearly not software loaded with rarely-used functions, but software that allow the applications to run nimbly. As such, companies should not rely on the sale of traditional products that they have used to date, but rather consider selling, for instance, limited-term licenses currently provided to corporations and using cloud services to customize services for individual user needs. In doing so, businesses are no longer solely transacting on the functionalities of products themselves, but developing a service-centric business model that takes into account customers' uses and benefits derived from the products.

Using this logic for businesses in developing countries opens new possibilities for Japanese corporations struggling against competition in terms of product costs. For example, in China, construction equipment manufacturer Komatsu commands a 
high market share in hydraulic excavators and large dump trucks used in mining. However, domestic manufacturer Sany Heavy Equipment recently increased its market share in low-cost equipment, intensifying market competition in that arena. Komatsu not only improved product durability and fuel efficiency but also used GPS functionality installed on construction equipment to gather data and provided services such as maintenance inspections and driving advice. From the user's perspective, owners can grasp real-time data on their equipment usage, while receiving precise information on parts replacement and maintenance inspection from Komatsu, reducing the probability of sudden equipment breakdown. This signifies Komatsu's service-centric model, focusing on the usability of its construction equipment. Thus, apart from the construction equipment being transacted, more importantly, specialized knowledge on maintenance timing and know-how on fuel efficient driving, acquired through data culled from equipment and stored in Komatsu's databases is being transacted. Unlike a typical one-way arrangement of a sale of goods from a manufacturer to a customer, data is communicated between the two parties as they use the equipment, thereby making the system user friendly. When customers acknowledge the additional value to products through these services, companies can break away from cost performance competition. In other words, they can maintain competitive advantage in developing countries with a more holistic business model rather than a standalone product model.

\subsection{Product Architecture and Technological Catch-Up}

When the level of quality and functionality of products manufactured by companies in developing countries lag behind Japanese companies in terms of technology, these companies exceed the level of customer demand; Japanese companies cannot compete with them by simple technology differentiation. The previous paragraph noted the effectiveness of shifting from a standalone product model to a customer value model. However, the Innovator's Dilemma is primarily encountered among electronic products with rapid technological innovation, and it is not seen in many other products. Japanese companies maintain a competitive edge through technological dominance in B2B products such as electronics components, high functionality materials, and industrial equipment. These products differ from B2C products in that they do not require conformance to the good-enough markets unique to developing countries and are difficult to commoditize. In addition, they may have unique manufacturing technologies and complex product structures, making it difficult for competitors to catch up. These product features can be summarized by the concept of product architecture (or design concepts). Herein, we examine the relationship between product architecture and technological catch-up by companies in developing nation, and clarify the implications for a global strategy within Japanese corporations.

Slowing the pace of technological catch-up by companies in developing countries requires lengthening the exclusive use of proprietary technology, methods of which include securing patents and intellectual property rights, preventing trade 
secret leaks, and reverse engineering via complex product structures. The most effective method varies by industry. For example, in the pharmaceutical industry, preserving rights via patents is effective, but in the electronics industry, many companies insist that product complexity works best (National Institute of Science and Technology Policy 2004). This is because pharmaceutical companies are able to protect their patent rights for compounds used in new medicines, while in the electronics industry, multiple patents exists for one product, and the know-how of the best combination of these technologies often becomes important. In addition, business systems are not in place to enforce local intellectual property rights when conducting business in developing countries, and while it may be necessary to acquire intellectual property, acquisition alone does not sufficiently protect technology. Thus, companies must take measures other than leveraging their intellectual property rights to maintain technological advantages. In particular, equipment-related products, such as consumer electronics, computers, automotive, and industrial equipment, can be internally analyzed by disassembling them, thus making them easy targets for imitation through reverse engineering. On the other hand, for manufactured products such as electronics components, high-function plastics, and steel plates, process technology is critical, and technology leakage can be controlled through technology management within factories.

Equipment-related products function as finished goods after being assembled from multiple components. When considering a product strategy with competition from companies in developing countries, the concept of product architecture (i.e., design concepts) is crucial. Product architecture is typically of two types: modular and integral. Modular architecture includes parts with little mutual dependencies and structures that are formed by assembling modules into finished goods. On the other hand, products with integral architecture have highly mutual dependencies among parts, and overall product structures are integrated and cannot be categorized into modules. Products with modular architecture can be manufactured by assembling parts procured from external sources, making it difficult to differentiate the finished goods on the basis of manufacturing technology. Accordingly, competitors are likely to catch up technologically with these products. Conversely, products with integral architecture require calibration between components of optimal assembly for the overall product, thus creating high entry barriers for companies from developing countries.

With the modularization of product architecture, the performance of each component and functionality are concurrently strengthened, resulting in a faster pace of innovation (Baldwin and Clark 1997). On the other hand, for products with integral architecture, groups responsible for each component jointly discuss how to improve the overall product, thereby increasing transaction costs. Thus, the pace of innovations is slower, but the finished product has an affinity to products that call for high quality and performance. This is because the design of each part and its assembly are optimized for the required performance and functionality. Specifically, electronic products, with their short lifecycles and rapid technological progress, have modular architectures, while automobiles, comprising several parts, requiring high quality and performance, are designed with integral architecture (Fujimoto 2005). 
As the modularization of product architecture progresses, interfaces between components are made public and specialists emerge who focus on the manufacturing of each component. The value added for each module increases relative to the value of the finished product, thus transforming a vertically integrated process of finished goods manufacturers to a process with horizontal division of labor and specialists for each module (Langlois 2002). Personal computers (PCs) are a typical example. A PC comprises a CPU, memory, a hard disk, a DVD player, a display, and other components, each developed by different companies and then assembled to function as a PC. However, there must be an industry agreement regarding the technological platform of the product we call a PC. For example, Intel, which provides the CPUs used in PCs, has become the primary driver for standardizing interfaces between components, and the technology they have developed is provided free of charge to other companies. Thus, as Intel creates faster CPUs, the overall performance of the PC will also improve (Gawer and Cusumano 2005). Thus, the modularization of product architecture requires the following: (1) a modular architecture for the entire product (as a design concept), (2) interfaces between components (modules), and (3) standardization to measure the performance of the overall module structure (Baldwin and Clark 1997).

The reason behind the progress in modularization within electronics-related products is because a product comprises many components and requires a combination of multiple technologies, making it difficult for one company to supply all necessary components and technologies. An industrial structure based on a horizontal division of labor increases the speed of innovation and rapidly improves product functionality and complexity. Despite the increasing product complexity, since the finished products can be assembled from components procured from external vendors, entry barriers for end-product manufacturers are low. Further, finished goods manufacturers have primarily labor-intensive work, such as processing and assembly, putting companies from developing countries at an advantage owing to the low worker wages in these countries. Taiwanese manufacturers, such as Acer, began as PC-assembly original equipment manufacturers (OEMs) for US companies; they then began designing products as original design manufacturers (ODMs), and finally moved on to supplying PCs to the market under their own brand names as original brand manufacturers (OBMs). In this manner, as finished goods manufacturers grew over time, electronic component manufacturers surfaced as supporting industries. As a result, Taiwan has become a large production region for electronic products (Sturgeon and Lee 2005). The progress of modularization in electronic products has given rise to electronic manufacturing services (EMS), which specialize in manufacturing. An electronic product can be completed by procuring components from external vendors and utilizing services provided by EMS for manufacturing, causing vertically integrated Japanese corporations to quickly lose competitiveness. On the other hand, cost competitive corporations from China and elsewhere have experienced astounding growth.

In industries where modularization has taken hold, strategies must be devised on a modular basis, rather than on a product basis, thereby making it difficult for companies in developing countries to catch up. Many electronic products have highly 
complex core components. In the case of PCs, Intel supplies the logic element, which is the core component. Similarly, Japanese companies have technologies such as optical pickup modules (a device that reads information stored on a DVD via a laser) in DVD players and inverter control devices in air conditioners. Many companies in developing countries are unable to easily copy these technologies. International competitiveness on a product-specific basis can be measured using external trade statistics and examining metrics of Japan's international competitiveness (exports - imports (trade balance) / exports + imports (total trade volume)). Finished goods, such as electronic equipment for consumer use and computers, have decreased across the board since the latter half of the 1990s, while metrics for electronics components have risen. In addition, Japanese electronic components manufacturers have increased their global market share (Motohashi 2010).

On the other hand, with regard to a product with an integrated architecture, an automobile is a prime example. The impact of the automakers is large among the value-added activities of the overall product (Fujimoto 2005). Automobiles are complex products comprising several parts that may be custom-made to the end manufacturers' specifications, which is contrary to electronic products, where completed products are made by assembling standardized components. New model development is accomplished by automakers collaborating with parts manufacturers on parts design. Entry barriers in this arena are high for companies in developing countries. In Europe and the US, parts suppliers' wages are relatively low compared with those of automakers, and the ratio of external sourcing of parts among vehicle manufacturers is said to be high to keep costs low (Takeishi et al. 2001). Nonetheless, overall product design is carefully managed by automakers, and as such, product architecture is not modular. However, new Chinese automakers Geely and Cherry began by assembling vehicles using parts bought from foreign automakers (a case of pseudo-open production) and gradually began their own development, technologically catching up with other automakers (Li et al. 2005). Still, the Chinese domestic market is dominated by foreign automakers, and vehicles manufactured by domestic automakers continue to demonstrate low quality and performance.

When considering competition strategies against companies in developing countries at a product level, companies must understand the characteristics of their products' architectures. Particularly in industries with a high degree of modularization, companies must choose strategies to build competitive advantage by focusing on modules that are technologically difficult to copy. However, modules that can be manufactured with a certain degree of quality by local companies are subject to cost competition, resulting in a quick price decrease. Among these are components, such as solar panels, for which manufacturing technology has been integrated into production equipment, enabling the implementation of production lines as turnkey systems. In industries with rapid technological innovation, companies must analyze not only the actions of competitors but also of related companies, such as materials and equipment suppliers.

In contrast, products with an integrated architecture make it difficult for companies in developing countries to catch up, giving Japanese corporations the luxury of time. However, companies in China and India are gaining strength, making it 
critical for Japanese companies to continually pioneer new technology. In addition, from the perspective of architecture theory, the emergence of electric vehicles poses a significant threat to the current automotive industry. Electric vehicles replace engines and transmission systems of traditional vehicles with motors and have a more modularized structure. There are various theories as to the potential ubiquity of these electric vehicles, but manufacturers must increase their competitiveness in core components (i.e., modules) in preparation for such a future.

\subsection{Business Models That Are Difficult to Be Imitated}

Products with highly modularized architectures are difficult to technologically differentiate, making it difficult for Japanese companies to compete against low-cost strategies adopted by companies in developing countries. Thus, we stated that, in developing countries, companies must consider a profit model at the modular level at which products are comprised. Is there any other way for Japanese companies to survive this environment? This section discusses shifting to an integration service that provides systems of one product combined with others, rather than standalone products.

First, we review the characteristics of business models by product architecture, as shown in Fig. 5.1. As previously stated, PCs are highly modularized products, though before their era, computers were products with integral structures. When IBM developed the System 360 in the 1960s, the design of computers became more

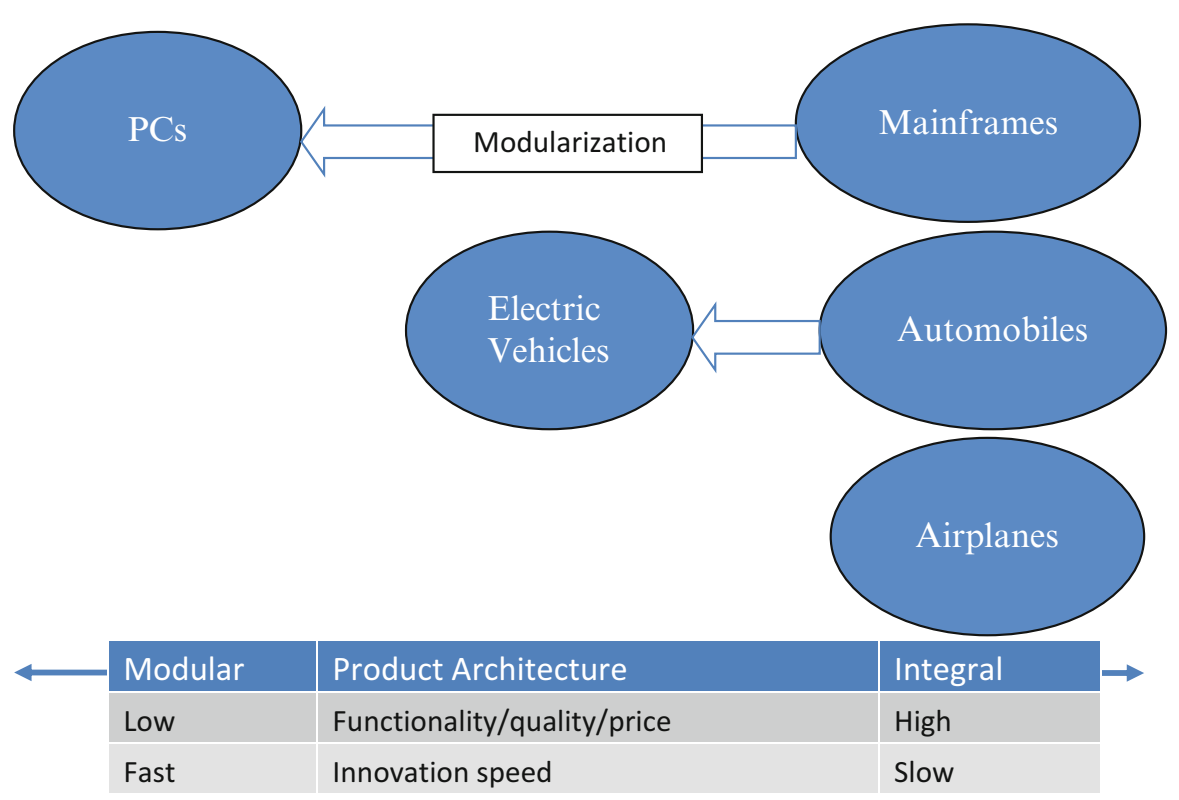

Fig. 5.1 Product architectures and business models 
modular, with components such as a CPU, input/output device, memory storage, and other components created to be less interdependent. This enabled the development of large-scale computers in a short period of time. This increase in system development efficiency paid big dividends for IBM (Baldwin and Clark 2000). However, the modularization of product architecture spurred the appearance of companies that specialized in each type of module, including IBM spinoffs, causing the downfall of IBM's vertical integration model used in mainframe computers. On the other hand, Intel developed a CPU for use in PCs - an act of destructive innovation for mainframe computers. The progress in modular PC technology has been dramatic, with mainframes currently being used only in applications that require high-speed processing of large volumes of data. Many information systems have been replaced by servers that have modular architecture.

On the other hand, as stated in the previous paragraph, automobiles continue to be products with an integrated architecture. However, in electric vehicles, many of the components required in traditional vehicles, such as fuel, gasoline engines, and transmission systems, will become obsolete and the number of parts will drastically decrease. In addition, interdependency between parts will also reduce, making electric vehicles modularized. As shown in Fig. 5.1, modularization triggers a horizontal division of labor in industry structures, with finished goods being made by assembling components. As a result, these products lack in performance shown by products that have an integral architecture, but having lower costs as market competition increases. Further, assembling finished goods becomes labor intensive; therefore, the increase of developing countries often spurs further cost reduction. On the other hand, with modular innovation, the pace of technological innovation in finished products becomes faster (Baldwin and Clark 1997). This results in reduced time requirement for product performance to exceed the level demanded by customers, increasing the likelihood of destructive innovation and further price erosion.

Product modularization results in a more competitive marketplace for companies from developed countries, including Japan. However, modularization in some types of products, such as airplanes, is unheard of. An airplane may have between one and two million different parts, making them more complicated than automobiles in terms of the order of magnitude. The process of developing new airplanes is of high duration. Airplane manufacturers procure parts from vendors only after completely thoroughly analyzing their technological characteristics. Airplane product technologies have matured to a certain extent, with interfaces that divide the parts, more or less fixed. However, the pace of performance improvements for each part differs, requiring an overall balance in the assembly of an optimized product (Brusoni et al. 2001). Greater modularization allows a faster pace of technological innovation because the modules encapsulate information inside and enable technological progress regardless of the status of other modules. However, internal encapsulation of information is not performed in airplane manufacturing, which requires manufacturers to consider the overall product composition after first understanding the technology of products procured from external sources. Therefore, airplane manufacturers and their parts vendors are loosely coupled. Airplane manufacturers 
are known as systems integrators because of their role in coordinating the overall system in all its scale and complexity (Brusoni et al. 2001).

Even within industries where modularization has progressed, Japanese companies may be able to sustain by playing the role of a system integrator. With the modularization of large computers with integral architectures, IBM's share prices fell drastically; however, IBM did not attempt to compete in the market with standalone products. Instead, they paved the way for a new path as a system integrator. Computer users have various IT systems needs. For example, a bank may wish to implement a high security accounting system that can quickly process large amounts of financial information. In this case, a system integrator will combine appropriate hardware and software catering to the needs of the bank to provide a suitable IT system to customers, thereby increasing the value of their products. IT systems are industry-specific, and with its large customer base, analyzing the appropriate system to meet an industry's needs is one of IBM's strengths. Know-how is a rare management resource absent among young companies. Corporations from developed countries, including those from Japan, have better business experience than companies from developing countries; similar management resources should exist from such business experiences. By moving from a business model based on outright sale of products to one based on customer service as system integrators, will enable these companies to build competitive advantage over companies from developing countries.

\subsection{Infrastructure Exporting as a Systems Integration Business}

According to METI, infrastructure investment between 2011 and 2020 in Asia is estimated at approximately USD eight trillion, of which $51 \%$ is estimated to be energy related, such as power generation; $31 \%$ to be transportation related, such as roads and railways; $13 \%$ to be telecommunications related; and $5 \%$ to be water and hygiene related (METI 2010). For example, India, a region of high economic growth, is only capable of meeting $80 \%$ of its electricity needs during peak demand times, resulting in frequent power outages in the country. India also suffers from a lagging road and railway infrastructure, which remains an obstacle to manufacturers entering the market. On the other hand, the capital requirement to invest in such future infrastructure demands exceeds the amount that the Indian government has budgeted, so expectations are high for private capital. For Japanese companies, this presents a significant business opportunity, and infrastructure exports have been highlighted in government growth strategies as an area that both the government and the private sector should undertake. We examine infrastructure exports as an example of system integration and evaluate ways to expand in developing countries.

Infrastructure services, such as roads, railways, water, and sewerage, are public utilities traditionally controlled by governments. However, in countries such as the UK and France, these services are outsourced to private undertakings through 
public-private partnerships (PPPs). While the responsibility to provide these services as public utilities may rest with the government, this arrangement is based on views that management by specialized businesses is more efficient; moreover, this aids in effectively incorporating taxes. Governments in developing countries lack the expertise and financial resources to efficiently manage such large-scale public services and mitigate the gap between infrastructure supply and demand. Thus, governments aim to employ the PPP system for infrastructure improvement. PPP businesses for infrastructure services often operate within a build, operate, and transfer (BOT) system. Thus, government organizations outsource the building and operation of infrastructure to private businesses, and subsequently, the ownership of infrastructure is transferred back to the country at the end of the outsourcing period. These are typically long-term projects that last 20-30 years and are high-risk businesses from the cash flow perspective, involving high expenditures in the initial construction period; these expenditures are then made up for through revenues generation from infrastructure operation over the long-term. A special purpose company (SPC) is typically established to run a BOT business. There are many dependent parties that profit from these projects-investors as the creditors that finance the business, public organizations requesting the business, plant operators, and others. PPPs for infrastructure services are large, complex systems that involve many different parties over a long period of time.

We now examine the characteristics of infrastructure businesses using a railway transportation service as an example. In addition to hardware infrastructure such as railcars, tracks, and train stations, providing transportation services for passengers or freight via railways requires operational and signaling expertise. The systems' components are not deployed using modules, but are instead designed in an integrated fashion, through mutual collaboration. For example, the UK revised its railway laws in 1993 and broad deregulation was implemented. Specifically, a public organization called "RailTrack" was created to consolidate infrastructure management, such as tracks, bridges, stations, and operational planning. Further, railway operations and ownership and maintenance of rolling stocks were outsourced to a private company. However, this arrangement caused various problems (Gayer and Davies 2000). For example, a company managing a particular line decided that it was appropriate to increase the speed of trains on that line to improve passenger service-a change that required a signaling system be installed in the rolling stocks. However, a leasing company, which leased to other railway operating companies, was separately involved with the railcars. Changing the signaling system of certain cars was inefficient for the leasing company, since, depending on the line, they would be forced to use other cars. Accordingly, the leasing company did not agree to the installation of this signaling system, and therefore the decision to increase the speed of the line was postponed, with parties unable to respond to differing circumstances and provide appropriate railway services. Issues such as the train schedule, signaling system, and rolling stock specifications form an integral structure, and an overall balance must be struck through mutual collaboration. Issues arose in this case when the operations providers were fragmented, and RailTrack was unable to function as a system integrator. 
The railway business provides a stable service through a purchase order that spans decades, requiring a flexible operating structure to respond to technological progress and economic situations. Consequently, the rolling stocks and signaling systems (i.e., the technological aspects) that comprise the service must be provided in unison with planning and management that are in sync with customer and freight transportation demand (i.e., the organizational aspects). Developing countries' capabilities to operate local railways is low; thus, there is a great need for an integrated system, from construction to transportation management, to be provided by developed countries. Japan provides high quality services in both long distance railways, as seen in the Shinkansen, or bullet train, as well as urban systems, as seen around Tokyo. Thus, the heightened demand for infrastructure in developing countries presents Japanese companies with significant business opportunities.

However, Japanese companies have had a late start in expanding the railway business in developing countries that would oversee projects from construction to management. The track record of Japanese companies to date consists primarily of projects under a "standalone product model," such as rolling stock's delivery, and few Japanese companies have been involved in railway operations. On the other hand, Alstom, Siemens, Bombardier, and other Western railcar manufacturers are aggressively chasing the package-style railcar business. In the 1990s, the EU used an open access policy for railroads to create a "top and bottom" organization, separating ownership and management of structures, such as tracks and stations, from operation of the railcars. As a result, a public organization was responsible for the infrastructure (the "bottom") as with the case of the UK, while railcar operations (the "top") were outsourced to private businesses. Thus, train manufacturers managed the railway service operations, becoming more competitive as railway service companies. On the other hand, beginning in the 1980s, Japan split railway companies by region as a means of reforming the national railways; the railway systems have been managed as one ever since, without "top" and "bottom" separation. Therefore, railcar manufacturers have not been able to build a knowledge base for operating railway businesses (Akizuki and Konagai 2010).

Accordingly, Japan Railways and private railway companies hold the key to future overseas expansions for the Japanese railway business. Taking advantage of Japan's strengths in railway services, namely its safety and accuracy in train management, requires the partnership of Japanese manufacturers to provide an integrated Japanese-style system as a package. However, the requirement of a high level of customer service is possibly higher in developed countries such as the US or Europe, rather than developing countries. A European team originally had the right of first refusal for the Taiwan High Speed Rail (the so-called Taiwanese shinkansen), which was designed as per European standards, but Taiwanese authorities were nervous about the design's earthquake resistance and ultimately chose Japan's shinkansen. This led to not only the purchase of railcars and management systems, but also to the dispatching of train conductors from Japan Railways to provide guidance. This is an example of Japanese companies providing railway services down to the operational level. In this case, a Japanese system was selected because of its geographical similarities with Japan's mountainous terrain and earthquake 
frequency. Infrastructure businesses such as railway systems need design and operation that respond to the geographical characteristics of each region. Therefore, it is imperative for companies to refine their targeted regions and formulate a proposal for such targets.

Moreover, Japanese companies must sort their technological (equipment and services) and organizational (management know-how) strengths, and clarify how each feature can enhance customer services. Package exports of an infrastructure business cannot merely be expanding Japanese business overseas as-is, considering the level of local customer demands and costs. Rather, companies need to filter the expertise required for core operations in current services, and then match that to the level demanded by the target region in terms of service levels and cost. In doing so, they must also consider how to differentiate themselves from their Western competitors and offer recommendations from the proposal stage that highlight the strengths of a coalition of Japanese companies.

\subsection{Conclusion}

In this chapter, we discussed how Japanese companies can best create business strategies while keeping in mind competition with local companies that emerge with the rise of developing countries, from the perspectives of a "customer value" model and product architecture theory.

The customer-centric model repudiates the corporation-leaning logic of "make good products and they will sell." It focuses on services provided by products and displays the concept of rebuilding business models from the perspective of improving customer value. A product-centric business strategy that chases product functionality and performance will lose effectiveness at a stage where product performance exceeds the level of customer demand. In developing countries such as China and India, "good-enough" product markets feature in a volume zone, and have a lower-than-average level of customer demand compared with markets in developed countries. Accordingly, competing with companies by using a strategy that emphasizes performance and functionality is difficult, and companies should instead design products and services from the perspective of maximizing customer value. The value customers seek from products is derived as they use those products. Thus, companies must focus on services derived from products and create business models that increase customer satisfaction across the product's lifecycle.

Next, companies must formulate strategies that correspond to the characteristics of product architecture. In particular, products with a modular architecture are easy for companies in developing countries to catch up with and will dramatically increase the competition faced by Japanese companies. In those situations, companies must consider strategies to improve the technology or differentiate products at the modular level. In addition, companies may take the opposite approach and become system integrators, providing valuable systems for customers by combining multiple products. As can be seen in system integration services for information equipment, customers have various needs, and providing turnkey services that 
optimally combine IT systems is characteristic of integral architecture. This is because of the expertise required to optimally combine these products to meet customer needs, rather than the performance of the components themselves.

In this chapter, we discussed the export of infrastructure business packages, such as railway services, as examples of system integration services. Providing railway services requires knowledge of signaling systems and railcar management, in addition to that of hardware infrastructure such as railcars, tracks, and stations. The fact that each system component is not modularized, but rather requires mutual collaboration for an integrated design, is characteristic of integral architecture. Japan's railway services have a high level of safety and accuracy. However, competition among railway operators is absent in Japan unlike Europe, and the passiveness shown by Japan Railways and other private railway companies in pursuing overseas expansion has caused Japan to fall behind in overseas expansion. Moving forward with an overseas business will first require Japan's railway operators to clarify the extent of their expertise on system integration and management. With that done, they must formulate proposals to countries and regions that make use of Japan's strengths.

Open Access This chapter is distributed under the terms of the Creative Commons Attribution Noncommercial License, which permits any noncommercial use, distribution, and reproduction in any medium, provided the original author(s) and source are credited.

\section{References}

Akizuki, S., \& Konagai, M. (2010, July). Kaigai no Tetsudou Operator to no Renkei wo Tsuujita Kokunai Tetsudou Gaisha no Kaigai Jigyou Senryaku Scenario, Chiteki Shisan Souzou. Tokyo: Nomura Research Institute, Ltd.

Ando, H., \& Motohashi, K. (2002). Nihon Keizai Kyoshoryoku no Koso. Tokyo: Nikkei Publishing Ltd. (in Japanese).

Baldwin, Y. C., \& Clark, K. B. (1997). Managing in age of modularity. Harvard Business Review, 75(5), 84-93.

Baldwin, Y. C., \& Clark, K. B. (2000). Design rules: The power of modularity. Cambridge, MA: MIT Press.

Brusoni, S., Prencipe, A., \& Pavitt, K. (2001). Knowledge specialization, organizational change and the boundaries of the firm: Why do firms know more than they make? Administrative Science Quarterly, 46, 597-621.

Christensen, C. (2001). The Innovator's Dilemma (trans: Shunpeita, T.). Shoeisha.

Fujimoto, T. (2005). Architecture no Hikaku Yui ni Kan suru Ichi Kousatsu (RIETI Discussion Paper Series 05-J-013). Research Institute of Economy, Trade, and Industry.

Gawer, A., \& Cusumano, M. (2005). Platform leadership (trans: Toshio, K.). Tokyo: Yuhikaku.

Gayer, A., \& Davies, A. (2000). Managing project-system interfaces: Case studies of railway projects in restructured UK and German markets. Research Policy, 29, 991-1013.

Langlois, R. N. (2002). Modularity in technology and organization. Journal of Economic Behavior \& Organization, 49, 19-37.

Li, C., Chen, J., \& Fujimoto, T. (2005). Chungoku Jidousha Sangyou to Seihin Architecture, Chungoku Seizougyou no Architecture Bunseki (T. Fujimoto, \& J. Shintaku, Eds.). Chapter 8, Tokyo: Toyo Keizai, Inc.

Ministry of Economy, Trade, and Industry. (2010, August). White Paper on International Economy and Trade 2010. Tokyo: Ministry of International Trade and Industry. 
Motohashi, K. (2010, April). Higashi Asia Electronics Database no Kouchiku to Nihon Kigyou no Kokusai Kyousouryoku no Bunseki (RIETE Discussion Paper Series 10-J-028).

National Institute of Science and Technology Policy. (2004, December). Report on the Japanese National Innovation Survey, Ministry of Education, Sports, Science and Technology National Institute of Science and Technology Policy (Ijichi, T., Iwasa, T., Odagiri, H., Keira, H., Koga, T., Goto, A., Tawara, Y., Nagata, A., Hirano, Y.)

Sturgeon, T., \& Lee, J. (2005). Industry co-evolution: Electronics contract manufacturing in North American and Taiwan. In S. Berger \& R. Lester (Eds.), Global Taiwan: Building competitive strengths in a new international economy (pp. 33-75). New York/London: M.E. Sharpe.

Takeishi, A., Fujimoto, T., \& Ju, C. (2001). Jidousha Sangyou ni Okeru Module-ka: Seihin, Seisan, Choutatsu System no Fukugou Hierarchy, CIRJE-J41. University of Tokyo Graduate School of Economics.

Vargo, S. L., \& Lusch, R. F. (2004). Evolving to a new dominant logic for marketing. Journal of Marketing, 68, 1-17. 